\title{
Public Perception of Information about Covid 19 on social media Instagram: An Netnography Study of Visual Information
}

\author{
Af'idatul Lathifah ${ }^{11}$, Riris Tiani ${ }^{1}$, Fadhila Mazida $^{2}$ \\ ${ }^{1}$ Lecturer at Faculty of Humanities, Universitas Diponegoro,Semarang \\ ${ }^{2}$ Undergraduate Student of Facultyof Humanities, Universitas Diponegoro, Semarang
}

\begin{abstract}
Information about Covid-19 circulating in the community has a crucial role in addressing this pandemic. The information about Covid 19 that was shared turned out to being great interest to the public so that it has many followers and verified as a trusted account by Instagram. People voluntarily follow these accounts in order to access Covid 19 information. Thus, people who follow these accounts have the awareness and willingness to be informed. This is certainly interesting in the midst of high public distrust of Covid 19, it turns out that on the other hand the community also voluntarily accesses information about Covid 19. To conduct this researchs we used netnography approach with blended method, involved 200 respondents from online questionnaires and 20 informants of virtual interview, observing informants' online activities and also account activities that spread information about Covid 19. Informations on Instagram account are considered more interesting, easier to check and more updates. $82 \%$ of respondents are interested in following information on the number of positive suspects every day. This interest can also be seen from the number of comments on related posts which are always the most. $84 \%$ of respondents admitted to spreading the information back to their families, but this information did not appear on the informants' social media accounts. Even though they always follow Covid 19 information, only $10 \%$ of respondents said they were afraid of this information.
\end{abstract}

\section{Introduction}

The pandemic caused by Covid-19 has been running for more than a year since the virus broke out in Wuhan City, China. In March 2020, the virus began infected Indonesian society. Since its inception, Covid 19 has reaped many pros and cons, and even some people do not believe that the virus is actual. Many thought that the pandemic Covid-19 was just a conspiracy. This assumption, of course, makes the handling of the pandemic becomes increasingly difficult. Poor public adherence to health protocols, stigmatization of sufferers, and refusal to vaccinate are obstacles to getting out of the pandemic.

Information about Covid-19 circulating in the community has a crucial role in addressing this pandemic. Schimdt (2020) notes that information plays a vital role in handling the Covid

\footnotetext{
* Corresponding author: afidatullathifah@gmail.com
} 
19 pandemic in South Africa. Incorrect information on social media could trigger fear, panic, and stigmatization of Covid 19 [1]. The onslaught of information about Covid 19, which focuses on positive confirmatory data and data on deaths, also can cause mental health problems in the community. Any media should be encouraged to provide more information about how to stop or slow down the spread of Covid 19 [2]. Studies in Russia said that $15.6 \%$ of student groups believe the rumours circulating about Covid 19[3]. This figure is, of course, very large, considering the rumours circulating regarding Covid 19 are also massive.

People got extensive information about Covid 19 through social media. Mass media such as television, online news website and newspaper are not very intensive in carrying information of the pandemic, mainly in the form of news on the handling and data of the pandemic. Unfortunately, social media provides the broadest possible freedom for anyone to display various kinds of information. In the end, the information circulating on social media is not always accurate and can even lead to hoaxes or fake news. With this much misinformation, WHO (World Health Organization) had raised concerns about an 'infodemic' or an information pandemic that exacerbated public misunderstanding of Covid 19 and also hindered the handling of this pandemic [4].

One of the social media used by Indonesians is Instagram. According to data released by Napoleon Cat, in the January-May 2020 period, Instagram users in Indonesia reached 69.2 million $(69,270,000)$. This achievement represents an increase of every month on the use of this photo-sharing platform (https://napoleoncat.com/). Social media that displays images or videos is certainly in demand because it can provide an attractive visual image. In addition, this platform also allows users to communicate with each other or respond via comments and likes or direct message (DM) features. Thus, other users can reply to or express responses to posts on Instagram.

The definition of social media has been carried out by boys and Nicole Elisson in their publication entitled "Social Network Sites: Definition, History, and Scholarship" in 2007. They refer to social media as "as 'networked publics' and suggested that they possessed four main affordances which were persistence, visibility, spreadability and searchability". This definition was certainly easily accepted at that time considering that several social media that were developing, such as Friendster and MySpace and then followed by Facebook, met the criteria as a platform that was a persistent public network, could be seen by anyone, was widespread and easily accessible. Sought [5]. At this time, social media is more emphasized in its definition and function as a forum that aims to form social networks and communication. In their anthropological study of social media, Boyd and Elisson emphasized that "What makes social network sites unique is not that they allow individuals to meet strangers, but rather that they enable users to articulate and make visible their social networks" [5].

Information about Covid 19 on Instagram social media is shared by various accounts, namely official accounts from the government such as the Ministry of Health official account (@kemenkes_ri) and the Covid 19 Task Force account (@ satgascovid19.id); accounts initiated independently by netizens in groups such as@ kawalcovid.id and @ pandemictalks, and personal accounts belonging to doctors, influencers or volunteers of Covid 19 such as @adamprabata and @ dr.tirta. The information about Covid 19 that was shared turned out to be of great interest to the public so that it has many followers and has been verified as a trusted account by Instagram, as evidenced by the presence of a blue checkmark on the account. Netizens must voluntarily follow these accounts in order to access Covid 19 information. Thus, netizens who follow these accounts have the awareness and willingness to be informed. This is certainly interesting in the midst of the high public distrust of Covid 19. It turns out that, on the other hand, the community also voluntarily accesses information about Covid 19. For these reasons, this article will discuss public perceptions of Covid 19 information on Instagram social media. 


\section{Method}

This study uses a blended method with a combination of ethnography and surveys. The survey was conducted on the follower social media accounts displays information about Covid-19,@kawalcovid.id and@pandemictalks. The survey involved 200 followers who filled out an online questionnaire that had been distributed. Netnography is a qualitative research method with an ethnographic approach seeing that the world of social media has the same culture as the real world. Social media users establish cultural norms and behave accordingly. In this study, Instagram followers who were respondents to the survey that had been carried out were then selected to be informants. The main informants were observed for their behaviour in social media, especially those related to Covid-19. Their responses to Covid-19 information posts and their daily behaviour on social media are the main data in the research. In order to access and explore this online consumer group, research adopted a netnographic approach. A research tool that takes advantage of the rapidly growing participation in online communities, candour and richness of these [6], these virtual worlds are legitimate as contexts of culture and meaning [7], and they are becoming more a part of overall and everyday social behaviour [8]. Wu and Pearce (2014) argue that netnography can be used to explore newly emerging phenomena, such as the post-postmodern authenticity negotiation considered here [9]. Michelle (2009) argues moreover that digital forum's unsolicited, spontaneous responses potentially offer a clearer picture of how fans actually make sense of reality TV depictions and offer insight into fan-initiated negotiations of meaning and significance [10].

\section{Result and discussion}

Research has proven good knowledge to be a significant predictor of correct practices in infection control [11]. In particular, the knowledge regarding symptoms of COVID-19 was good. About 93\% were well aware, and around $79 \%$ knew that there is only supportive treatment available for the virus; both these findings were in accordance with a study from Jordan [12]. Survey results from online questionnaires distributed to followers of Instagram social media accounts displaying information about Covid-19 show that most of these followers are highly educated. As many as $61.1 \%$ are undergraduate graduates, and $15.2 \%$ are master graduates. Most of them said they were interested in following the Covid 19 information from Instagram because it was presented in an attractive visual form, such as animated images, diagrams, or videos.

These followers voluntarily follow the Instagram account to get updated information about Covid $19.83 .3 \%$ of respondents are active social media users who have used social media for more than 5 years. This long period makes them quite astute in social media. Informants frequently update their Instagram feed, create Instagram stories and also comment on posts from other users. Thus, they also follow various kinds of things that are happening in this world from social media. One of them is the Covid 19 pandemic. As many as $82.2 \%$ of respondents claimed to have followed Covid 19 information on social media since the beginning of the pandemic. $18.2 \%$ only followed one account, the remaining $25.3 \%$ of respondents followed 2 accounts, and $21.2 \%$ followed 3 accounts. The other respondents follow more than 3 Instagram accounts. They admit that they check information every day about Covid 19 on Instagram. As many as $82.3 \%$ of respondents said that positive suspect information for Covid 19 was the most awaited information. Apart from personal consumption, as many as $84.8 \%$ of respondents will share the information again, especially with their family and closest people.

The activities of followers on various Covid 19 Instagram accounts have also been scrutinized. Most comments are often found on posts that contain information about the number of positive suspects daily. For example, on the@ @awalcovid.id account, which indeed routinely posts the number of positive suspects daily, comments on these posts on average penetrate more than 50 comments every day. On the @pandemictalks account, information about the number of positive 
suspects and the emergence of new clusters on average received more than 200 comments. In contrast to posts about vaccination updates and information about health protocols, both followers received very little response. On the @ dr.tirta account, a doctor, influencer and entrepreneur, the account is not specifically made to provide information about Covid 19. However, the Covid, 19 information on that account, is always the most responded to than other posts. Other types of posts that get much response contain controversial information, such as information about government policies and hoax news circulating in the community.

The comments that appear on posting the number of positive suspects Covid 19 can be categorized into 3 types:

Table 1. Type of Comments.

\begin{tabular}{|l|l|}
\hline Type of comments & Contents \\
\hline Affirmation & Are there still people who don't believe in \\
& Covid 19? \\
& If you haven't contracted Covid 19, you \\
won't believe it & Waiting for the covidiot (people who don't \\
& believe in Covid 19) to emerge \\
\hline Concerns & There are still many who ignore health \\
& protocols \\
& The closest people do not believe Covid 19 \\
& Data fluctuates, when will the pandemic \\
& end? \\
\hline Distrust in Covid 19 & All diseases are associated with Covid 19 \\
& Deaths from other diseases are greater than \\
& Covid 19 \\
& Only lied and scared by the media \\
\hline
\end{tabular}

Interestingly, the accounts created independently by netizens are even more active than government official accounts, such as the@ kemenkes.ri and@ satgascovid.id accounts. Even though the two of them also shared information about Covid 19, netizens still have not responded to it actively. This can be seen from the number of comments in each post. Netizen initiation account activity is also more intensive than official government accounts. The @ satgascovid.id account has 326 posts with 201,000 followers, while the @ kawalcovid.id account has 1,634 posts with 280,000 followers and the @pandemictalks account has 776 posts with 234,000 followers. This can be a measure of public confidence in the handling of Covid 19 by the government, which until now is still considered low. Comments on official government accounts also contain public distrust of Covid 19. On the @ kawalcovid.id and @ pandemictalks accounts, negative comments that do not believe Covid 19 will be replied to by other followers with ridicule or proof that Covid 19 is true vice versa the account. @kemenkes_ri and@ @atgascovid.id many similar comments were responded to with support from other followers. Conversely, when independent accounts are considered to support government policy, some followers tend to accuse the account of being affiliated or financed by the government. Although there were not many, several apathetic comments appeared on the independent account.

In an online survey conducted, as many as $50 \%$ of respondents said they were not afraid of information about Covid 19. Only $10.1 \%$ of respondents felt scared because of the Covid 19 information they received. However, $97 \%$ of respondents stated that this information made them more cautious. Even so, $45.5 \%$ of respondents still think that Covid 19 is a dangerous disease, and $44.9 \%$ think it is hazardous. Followers of Instagram accounts containing Covid 19 information also claim to always comply with health protocols. Thus there is a positive correlation between Instagram followers and adherence to health protocols. 
In the context of communication through social media, characteristics indicating credibility can strengthen the appearance of professionalism and thus increase patients' trust in professionals in the health field.

"I have been following the @pandemictalks account since October 2020 because the account appears in explorer. I think the content is interesting, the pictures are good, so it is easier to capture the content. We also have to find information from reliable sources. You also like to read the comments. Sometimes the organizer also includes interesting or funny (controversial) comments, which are responded to by many other followers. For me, I like to see and read, but I do not always comment; most of all, I like it. The information is beneficial, and sometimes it's sad that there are still people who don't believe in Covid 19, even though it is clear that there have been many victims. If it is like this when Covid ends, you are tired of following health protocols, but if you don't (following health protocols), you are afraid of contracting too" (@RM)

"I follow the@ kawalcovid.id account because in the past I also followed kawalpemilu.id. I do not want to be a covidiot (people who believe that Covid 19 is just a conspiracy). I want to protect my family and the people around me too. So if there is interesting information, I often share it on the IG storey or the WA status. I open Instagram every day, so almost every day, I see Covid 19 information, especially if @ kawalcovid.id updates data every day. I like excitement when I see the case going up again; oh my, which one is high. But the point is I have to adhere to health protocols for me personally, the hope is that the pandemic will end quickly, but if you look at the number of positives, it is uncertain, so it is a bit pessimistic" (@DL)

"I am a Covid 19 survivor, I did not expect to be hit too, so I also follow the @ pandemictalks account because I have experienced it, so I sometimes relate to what is posted on that account. It looks like a doctor also manages the account, huh. During the treatment period, I also always posted on Instagram stories, how the symptoms were, how was the pain, how was the treatment process. Alhamdulillah, many support and I also educate the people around me to be aware of Covid 19. Even though I have been infected with Covid 19, I still have to be vigilant" (@UB)

Followers of the Covid 19 information account follow these accounts with complete awareness to get correct information about Covid 19. This information makes them more aware of Covid 19 and keeps them adhering to health protocols. However, followers' activities on their accounts often do not share information or activities related to Covid 19. Personal accounts have started to use many profile photos wearing masks, but they often post photos without masks in their daily activity content. The activities carried out also did not look different from those before the pandemic, such as working, travelling, hanging out with friends, or sports. Thus, the information about Covid 19 received by the public is often only used as personal information.

\section{Conclusion}

The Covid 19 pandemic still infects Indonesia; the emergence of various social media accounts informing about Covid 19 is in great demand by the Indonesian people, as evidenced by a large number of followers of this account. Information from Instagram is considered more exciting and easier to follow, especially for active social media users. The information presented, especially regarding the development of the increase in cases of Covid 19 infection, has become a reference for responding to pandemic conditions; followers are becoming more vigilant and trying to follow health protocols. Low public trust in the handling of the pandemic by the government is also seen in the activity of the government's Covid 19 account. The public often leaves negative comments and distrust on these accounts. This is in contrast to the independent accounts of community initiatives which receive more positive comments. 


\section{Policy recomendations}

The government needs to encourage community initiatives to disseminate correct information about Covid 19. The public trusts more information that is independent and delivered by competent professionals. The better the public receives trusted information, the greater the compliance with health protocols and efforts to prevent disease infections, especially Covid 19. The government must also share Covid 19 information through its official account more actively and attractively, encouraging account managers to interact with followers to build trust. Against the government's efforts to deal with a pandemic.

\section{References}

1. Schmidt, T., Cloete, A., Davids, A., Makola, L., Zondi, N., \& Jantjies, M. Myths, misconceptions, othering and stigmatizing responses to covid-19 in south africa: A rapid qualitative assessment. PLoS ONE, 15(12 December) doi:10.1371/journal.pone. $0244420(2021)$

2. Su, Y. (2021). It doesn't take a village to fall for misinformation: Social media use, discussion heterogeneity preference, worry of the virus, faith in scientists, and COVID19-related misinformation beliefs. Telematics and Informatics, 58 doi:10.1016/j.tele. 2020.101547 (2021)

3. Klimova, A. M., Chmel, K. S., \& Savin, N. Y. (2020). Believe it or not: Public opinion and rumors about covid-19. [ВЕРЮ-НЕ-ВЕРЮ: ОБЩЕСТВЕННОЕ МНЕНИЕ И СЛУХИ О ПРОИСХОЖдЕНИИ НОВОГО кОРОНаВИРУСа] Monitoring Obshchestvennogo Mneniya: Ekonomicheskie i Sotsial'Nye Peremeny, 2020(6), 266283. doi:10.14515/MONITORING.2020.6.1752 (2020)

4. Su, Z., McDonnell, D., Wen, J., Kozak, M., Abbas, J., Šegalo, S., Xiang, Y. -.Mental health consequences of COVID-19 media coverage: The need for effective crisis communication practices. Globalization and Health, 17(1) doi:10.1186/s12992-02000654-4 (2021)

5. Miller, D., Costa, E., Haynes, N., McDonald, T., Nicolescu, R., Sinanan, J., . . . Wang, X. (2016). Academic studies of social media. In How the World Changed Social Media (pp. 924). London: UCL Press. (Retrieved February 15, 2021)

6. Mkono, M. and Markwell, K. 'The Application of Netnography in Tourism Studies', Annals of Tourism Research 48: 289-91 (2014)

7. Sumiala, J.M. and Tikka, M. 'Broadcast Yourself - Global news! A netnography of the "Flotilla" News on YouTube', Communication, Culture \& Critique 6(2): 318-35 (2013)

8. Kozinets, R.V. Netnography. Hoboken, NJ: John Wiley \& Sons, Inc. (2015)

9. Wu, M.Y. and Pearce, P.L. 'Chinese Recreational Vehicle Users in Australia: A Netnographic Study of Tourist Motivation', Tourism Management 43: 22-35. (2014)

10. Michelle, C. '( $\mathrm{Re})$ contextualising Audience Receptions of Reality TV', Participations 6(1): 137-70. (2009)

11. Chen S, Qiu Z, Xu L, Chen J, Lin Y, Yang Y, et al. People groups' responses to SARS in the community. Chin Rural Health Serv Adm. 2003;23: 15-8.

12. Alzoubi H, Alnawaiseh N, Al-Mnayyis A'a. Mohammad Abu- Lubada, Amin Aqel and Hani Al-Shagahin, COVID-19 - knowledge, attitude and practice among medical and non-Medical University students in Jordan. J Pure Appl Microbiol. 2020;14(1):17-24

13. Chretien KC, Tuck MG. Online professionalism: a synthetic review. Int Rev Psychiatry Informa Healthcare. 2015;27:1 06-17 